\title{
METHYL IODIDE POISONING
}

\author{
BY \\ ANDERSON GARLAND and F. E. CAMPS \\ From Burton Road Hospital, Lincoln, and the Chelmsford and Essex Hospital
}

\section{Toxicity of Methyl Derivatives}

It is becoming increasingly obvious that all methyl derivatives are highly toxic substances. It has long been known that methyl alcohol is dangerous since it occupies a peculiar place among solvents on account of the temptation to use it as a beverage. The most prominent symptom has been amblyopia followed by blindness which is frequently total and permanent and caused by a primary optic atrophy, but less severe exposure may cause acute gastrointestinal disturbance, headache, vertigo, feeling of intoxication and dilated pupils, while severe exposure may be followed in a short time by giddiness, unconsciousness, sighing respiration, depressed cardiac action, cold sweats, violent delirium, coma and death. Recently Jacobson, Russell, Grimm and Fox (1945) and Kaplan and Levreault (1945) have reported 60 cases of methyl alcohol poisoning occurring in the Pacific theatre of war where Japanese have been using the substance as a fuel. American soldiers have found drums containing remnants and used it as a drink mixed with fruit juices. Sixteen of the cases were fatal.

Røe (1943) suggested that the action of the poison could be attributed to the inhibition of oxidation processes by formic acid, which forms a complex compound with iron. The process is followed by an acidosis which is mainly due to lactic acid. Amblyopia does not occur until the acidosis is well established except in the presence of strong light. Increase of metabolism may provoke or aggravate amblyopia since it increases the acidosis. The oxidation of methyl alcohol is checked by the consumption of ethyl alcohol; and all signs of poisoning may be averted if it is drunk before or repeatedly after the consumption of methyl alcohol. Treatment consists firstly in counteracting the acidosis by the intravenous injection of isotonic sodium bicarbonate. Much fluid by mouth combats dehydration and promotes diuresis and loss of chloride may be counteracted by 5 per cent. glucose in saline. Gastric lavage should not be undertaken until the intravenous sodium bicarbonate is started. Ethyl alcohol helps to prevent recurrence of acidosis. The eyes require protection against light during the acute stage of the poisoning and if amblyopia persists.

Methyl chloride is a colourless gas with a faint ethereal odour. It is used in the dye industry and in the preparation of chloroform, and to an increasing extent it is replacing ammonia and sulphur dioxide in refrigeration. In 1927 and 1930 Baker described 96 cases of poisoning amongst employees of an American firm of refrigerator manufacturers, and Kegel, McNally and Pope (1929) gave a full account of the symptoms based on 29 cases, of which 10 were fatal. Jones (1942) gave an account of seven cases which had occurred in Great Britain among travelling refrigerator repairers. In mild cases, the symptoms include staggering gait, dizziness and headache, followed the next day by anorexia, nausea and vomiting, which are not as a rule severe enough to prevent the man from working. In more severe cases, the patient may be ill for weeks, the staggering and dizziness being accompanied by drowsiness, malaise and weakness. In about half the cases, ocular symptoms, consisting of misty vision, diplopia, and difficulty in accommodation occur after about 24 hours, and may persist for two months. Vomiting is sometimes most persistent and may last up to a week or ten days. Diarrhoea is described. In the most serious cases epileptiform convulsions occur and may lead to death. Involuntary movements include myoclonus and action tremors. Ptosis, strabismus, and diplopia are common, but optic atrophy does not occur. Slurred speech, amnesia, drowsiness by day, and delirium by night occasionally seen. The temperature, pulse and respiratory rate are raised, and in the worst cases there is oliguria and suppression of urine. Albumen and red cells occur in the urine in at least half the cases. No case has shown jaundice though fatty degeneration of the liver has been seen at necropsy. In some cases the red cell count fell as low as $3,100,000$ per c.mm., and the haemoglobin to 50 per cent.; sometimes there is a leucocytosis. Sequelae such as ataxia, diplopia, misty vision, headache, drowsiness and amnesia may persist for as long as eight months. Poisoning in refrigerator factories can be prevented by adequate exhaust ventilation; but it is difficult to explain to the refrigerator repairer that an almost inodorous nonirritating gas is poisonous. He must be forbidden to stay in a room after he has heated liquid methyl chloride in the blocked evaporator of a refrigerator. Warning of a leak from a refrigerator might be given to a householder by adding a pungent detector 
substance such as acrolein, but it is probable that methyl chloride will soon be replaced in refrigerators by freon (dichloro-difluoro-methane) which is equally efficient and is harmless.

Methyl bromide is an important fire extinguisher, fumigant, refrigerant, and delousing agent, and recently many cases of poisoning have been reported. (Watrous 1942, Miller 1943, Gray 1944, Holling and Clarke 1944, De Jong 1944, Heimann 1944, Clarke, Roworth and Holling 1945, Wyers 1945, Butler, Perry and Williams 1945, Michaux, Clercy and Lechevallier 1945, and Duvoir and Dérobert 1945.) The toxic effects fall into three distinct groups, those brought about by pure gassing, the systemic effects of the vapour, and the effects on skin and mucous membranes. In the first instance death may occur from anoxaemia or toxic paralysis of the respiratory centre. Mild systemic effects include headache, giddiness, numbness, fits, diplopia, inability to accommodate, and vomiting; severe effects include signs similar to alcoholic intoxication with disorders of gait and co-ordination. Methyl bromide rapidly penetrates clothing, including leather and rubber, and has an irritant effect on skin and mucous membranes, producing burns characterized by enormous blisters containing sterile fluid. Depression and sleeplessness are frequent features of the convalescent period. Usually symptoms run parallel to the non-volatile bromine level in the blood which may be raised from a normal not exceeding $1.5 \mathrm{mg}$. per cent. to $10 \mathrm{mg}$. The bromine content in the cerebro-spinal fluid may also be raised from a normal of $1 \mathrm{mg}$./ $100 \mathrm{ml}$. to 15 or more $\mathrm{mg}$. $/ 100 \mathrm{ml}$. Death, when it occurs, usually results from pulmonary oedema, and necropsy findings include acute purulent bronchitis, inflammation and oedema of the lungs, fatty degeneration of the ganglion cells of the brain and degenerative changes in the kidneys.

In 1940 Hunter, Bomford and Russell recorded four cases of poisoning by inhalation of methyl mercury iodide in a factory where fungicidal dusts were manufactured. The symptoms were entirely different from those of inorganic mercury poisoning, and resembled much more the nervous symptoms associated with methyl derivatives. They consisted of severe generalized ataxia, dysarthria, and gross constriction of the visual fields, while memory and intelligence were unaffected. Animal experiments showed that there was an intense and widespread degeneration of certain sensory paths of the nervous system, the peripheral nerves and posterior spinal roots being affected first, the posterior columns and the granular layer of the middle lobe of the cerebellum later.

\section{Toxicity of Methyl Iodide}

Methyl iodide is not extensively used and therefore few cases of poisoning have occurred. The only one reported in the literature is by Jaquet (1901). He recorded the case of a man, aged 30, who developed methyl iodide poisoning whilst employed in a dye-works. The symptoms were vertigo, diplopia, and ataxia, the patient swaying as if drunk. Chemical tests of the urine gave a strong reaction for iodine. When delirium and mania ensued treatment in a mental hospital was necessary. Mental dullness persisted and the man, unable to resume his work, was given the task of gate attendant, but up to the present time no case of methyl iodide poisoning has been recorded in Great Britain.

Methyl iodide is used as a half-way product in making certain other preparations. It is a colourless acrid liquid with a boiling point of $42 \cdot 5^{\circ} \mathrm{C}$. and melting point of $-66.1^{\circ} \mathrm{C}$; it is 1.4 per cent. soluble in water and completely miscible with alcohol and ether. It is lachrimatory. At the factory where the present case occurred it was prepared by the interaction of dimethyl sulphate and sodium iodide in a still, the methyl iodide being collected over water in an open pan. The still was heated by means of a steam coil and the methyl iodide carried in an open vessel and poured into a carboy. It was an open method and undoubtedly exposed the workman to the fumes of methyl iodide, but at that time the risks were not appreciated and now the method is entirely enclosed.

\section{Case Record}

An account is given of the case of a worker on this process who developed the symptoms of methyl iodide poisoning.

A man aged 38 was employed in a chemical factory manufacturing methyl iodide. On December 12, 1940, he complained of giddiness, sleepiness and diarrhoea. There was some mental irritability accentuated by noise. He ceased work and was attended by a doctor, recovery occurring at the end of one week. The man remained well and resumed his work on March 10, 1941, but towards the evening of that day he developed vomiting and drowsiness. He saw the first-aid attendant who described him as looking pale and somewhat intoxicated.

The patient was admitted to hospital on March 11 when he was found to be drowsy and unable to walk. The speech was slurred and incoherent. There were nystagmoid movements of the eyeballs to the left and a slight degree of right internal strabismus. The fundi were clear. The muscles of the upper limbs twitched and the lower limbs were spastic. The abdominal reflexes were absent, but the deep reflexes and plantar responses were normal. The output of urine was reduced, only 1 pint being passed in 24 hours; it contained $9 \mathrm{mg}$. of combined iodine per 100 c.c., but no bromine or methyl alcohol. Lumbar puncture was performed on two occasions. A total of 20 c.c. of cerebrospinal fluid was withdrawn and found to be normal. There was no evidence of iodine, bromine or methyl alcohol on chemical examination. On March 13 vomiting, restlessness and incontinence occurred. From that time onwards the patient became comatose and the limbs flaccid, death taking place on March 18.

At the autopsy all the organs were seen to be congested, apart from the heart which was pale and flabby. There was broncho-pneumonia. Microscopic examination of the lungs showed areas of broncho-pneumonia and haemorrhages. The tissue around many small arteries was infiltrated with lymphocytes and plasma cells. Section of the brain showed congestion but nothing more. Chemical examination of the brain yielded a total of $6 \mathrm{mg}$. of combined iodine.

It will be seen that there is a striking resemblance between methyl iodide poisoning and poisoning with 
methyl chloride and methyl bromide. This is only to be expected, but little confusion should arise in diagnosis since it is probable that it will be known to which of the three compounds the patient has been exposed. Further chemical examination of the urine, blood or cerebro-spinal fluid will reveal which of the halogens is present in excess.

Dimethyl sulphate from which methyl iodide is manufactured is a toxic substance but little diffculty is likely to arise here since the symptoms are entirely different. The fumes of this substance cause oedema of the mucous membranes which usually subsides in a period of 10 days; the symptoms include conjunctivitis, oedema of fauces and uvula, making swallowing difficult, and cough. There are no abnormal signs in the central nervous system and the mentality is unclouded.

\section{Prevention}

Everything depends on prevention. Legge (1934) emphasizes as one of the guiding principles of industrial medicine that all workmen must be informed of the dangers associated with the material used, and that they should not be left to discover their poisonous action by bitter experience. Due precautions have been taken with dimethyl sulphate, but methyl iodide has not always been regarded as dangerous, the product being ladled into containers by operatives with no gloves or masks. Workmen find it irksome to wear masks for long hours so that intervals of rest are essential. 'Festina lente' must be the motto for employers who wish to have the maximum work performed without risking the lives of others.

Adequate ventilation is essential and in war-time black-out regulations may interfere with this. Irritant gases such as chlorine soon give warning of their presence, but when the poisonous substance is inodorous the first sign may be sudden loss of consciousness. Cages containing mice or birds placed at danger points should prove of assistance in the early detection of poison gas, but chemical tests are preferable and a 'Halide' Detector Lamp can be employed to discover the presence of organic halogen compounds. The Department of Scientific and Industrial Research (1940) has issued a leaflet on the subject, but methyl iodide is not listed, and it is also to be noted that methyl bromide may give rise to acute symptoms in concentrations below that which can be detected by the lamp. Defects in the working of machinery may occur even in the apparently perfect factory. It is when these appear that the risk is greatest. Routine precautions are apt to be forgotten when the unexpected problem arises. More than once rescuers have themselves fallen victims by forgetting to remove the patient immediately symptoms have become manifest.

\section{Treatment}

Although lumbar puncture was performed for diagnostic purposes in the case recorded, it was hoped that it might prove to be a therapeutic measure combined with rectal injections of hypertonic magnesium sulphate. However, the cerebrospinal fluid was not under increased pressure so that the treatment found little support from the theoretical point of view. Some halogen derivatives have caused neuritis. It was therefore decided to try vitamin $\mathbf{B}_{1}$. Injections of massive doses were employed with no appreciable effect.

\section{Summary}

A case of methyl iodide poisoning is described. The signs and symptoms included nausea, vomiting, diarrhoea and oliguria, vertigo, slurred speech, visual disturbances, ataxia, tremor, mental irritability, drowsiness and coma.

Methyl iodide is prepared from dimethyl sulphate and the symptoms of exposure to the latter are recorded.

It is shown how closely methyl iodide intoxication resembles that of methyl bromide and methyl chloride, whilst confusion with acute alcoholism could occur in all three types of poisoning.

Some features of prevention and treatment are presented.

\section{Acknowledgments}

We wish to thank Dr. Donald Hunter for the reference to Jaquet's paper, and Dr. William Bullough, M.O.H. for Essex, for permission to publish the case.

\section{REFERENCES}

Baker, H. M. (1927). J. Amer. med. Ass., 88, 1137. - (1930). Amer. J. publ. Hith., 20, 291

Butler, E. C. B., Perry, K. M. A., and William, J. R. F. (1945). Brit. J. industr. Med., $2,30$.

Clarke, C. A., Roworth, C. G., and Holling, H. E. (1945). I Ibid., 2, 17. De Jong, R. N. (1944). J. Amer. med. Ass., 125, 702. Duvoir, M., and Derobert, L. (1945). Arch. Mal. profess., Gray, P. H. K. (1944). J. roy. nav. med. Serv., 30, 214.

Heimann, H. (1944). Industr. Bull., 23, 103.

Holling, H. E., and Clarke, C. A. (1944). J. roy. nav. med. Serv., 30 , 218.

Hunter, D., Bomford, R. R. and Russell, D. S. (1940). Quart. J. Med. 9,193

Jacobson, B. M., Russell, H. K., Grimm, I. J., and Fox, E. C. (1945). Nav. med. Bull., 44, 1099

Jaquet, A. (1901). Dtsch. Arch. klin. Med., 71, 370.

Jones, A. M. (1942). Quart. J. Med., 11, 29.

(1945), Nav med Bull., 44, 1107. Kegel, A. H., McNally, W. D., and Pope, A. S. (1929), J. Amer med. Ass. 93, 353 .

Legge, T (1934) Industrial Maladies. Oxf Univ Press, $p .3$. Michaux, J., Clercy, A., and Lechevallier, G. (1945). Arch. Mal. profess 6,143 . Mrofess., 6, 143

Miller, J. W. (1943). Arch. Pathol., 36, 506.

Røe, O. (1943). Acta. med. scand., 113, 558.

Wyers, H. (1945). Brit. J. industr. Med., 2, 24. 